\title{
Pregnancy related complications and its association with socio-demographic factors in Central India: A logistic regression hypothesis
}

\author{
Dinesh Kumar $^{1 *}$, T.B. Singh ${ }^{2}$, Pawan Ghanghoria ${ }^{3}$, Vineeta Ghanghoria ${ }^{4}$ \\ ${ }^{1}$ Scientist E, $\mathbf{2 , 3 , 4}$ Professor, ${ }^{3}$ Dept. of Pediatrics, ${ }^{4}$ Dept. of Gynecology, ${ }^{1}$ ICMR-National Institute for Research in Tribal Health (NIRTH), \\ Jabalpur, Madhya Pradesh, ${ }^{\mathbf{2} I n s t i t u t e ~ o f ~ M e d i c a l ~ S c i e n c e, ~ B a n a r a s ~ H i n d u ~ U n i v e r s i t y ~(B H U) ~ V a r a n a s i, ~ U t t a r ~ P r a d e s h, ~}{ }^{\mathbf{3} 4}$ Netaji Subash \\ Chandra Bose Medical College, Jabalpur, Madhya Pradesh, India \\ *Corresponding Author: Dinesh Kumar \\ Email: drdkumar1970@gmail.com
}

\begin{abstract}
Maternal health research is vitally important required to find out the obstetric complications for effective treatment and strategy in support to enhanced women \& child health. It is much essential in vulnerable tribal population which have less opportunity to avail health care facility due to illiteracy and poor socioeconomic condition. The complications during pregnancy and childbirth cause had more deaths and disability than any other reproductive health problems. A cross sectional study was carried out among the Baiga women in Dindori district of Madhya Pradesh during 2013 to 2016. A sample of 367 currently married who had experienced maternity during last three years were identified for pregnancy related complications. The information was collected by interview method after obtaining informed written consent. Out of 367 women, the multiple complications were found anemia (35.7\%), night blindness (28.6\%), blurred vision (10.9\%), convulsion $(21.3 \%)$, swelling $(26.7 \%)$, excessive fatigue $(4.6 \%)$ and vaginal bleeding $(4.9 \%)$. The logistic regression analysis were done to estimate the level of correlation between socio-demographic factors and obstetric complications. The findings revealed that the night blindness, anemia and blurred vision complications were found significantly $(\mathrm{p}<0.05)$ associated with younger $(20-29$ years $)$ and elderly (30 years and above) women while vaginal bleeding strongly associated $(\mathrm{p}<0.01)$ with elderly women only. The high birth order, lower age at marriage, illiteracy were found more likely to arise the complications. The socio-demographic factors influenced to the risk of complications. The IEC education can empower and force to women for the effective treatment during pregnancy.
\end{abstract}

Keywords: Pregnancy, Complication, Logistic regression analysis, Vulnerable population, Central India.

\section{Introduction}

A pregnant women needs adequate rest for growth of the baby and regular ANCs during pregnancy are essential for a healthy baby and healthy mother. Since the growth of baby starts from pregnancy itself and care during pregnancy, delivery controls the better outcome. Generally, most of the pregnancies are smooth and uneventful but some pregnant women may have problems/complications which indicate risk of the mother and the baby. Thus the incidents of complications during pregnancy and delivery is obvious and leads as major cause of death of mothers. Globally, the maternal mortality is the most important cause of death in reproductive age (15-49 years). The proper pregnancy care with quality in timely as per standard norms can influences the healthy outcome. The traditional practices in rural area having the most common reason for conducting child birth at home ${ }^{1}$. Scenario of globally, 2.7 million babies die during neonatal period (the first month of life-newborn) and 2.6 million babies are stillborn. ${ }^{2}$ The grounds and cause behind that the effect of pregnancy, childbirth or the effect of utilization of maternal health care services. Although the use of maternal health care services is a proximate determinants of maternal morbidity and mortality.,4 In this regards, the concerned studied reported that approximately $80 \%$ of maternal deaths and $98 \%$ stillbirth have been caused by direct obstetric complications; primarily hemorrhage, sepsis, complications, abortion, preeclampsia, eclampsia \& prolonged/obstructed labour. ${ }^{5-7,10}$ For the maternal deaths and other pregnancy outcomes, obstetric complications defined as a predictor. A threatened miscarriage defined as vaginal bleeding before 24 week of gestation, is a complication affecting about $20 \%$ of pregnancies in India. ${ }^{11}$ Subsequently, for the obstetric complications in the lowincome setting have serious consequences in terms of both socially \& medically. ${ }^{16,17}$ Although, India has made extensive efforts as many programme \& policies to curb down the maternal mortality lined up to develop the health condition of women to achieve MDG-5 and in some regions much progress has been achieved. In this the status of India, maternal mortality ratio dropped from 600 in 1990 to 390 in year 2000 and to 200 in 2010 existed. $^{18}$ The Madhya Pradesh have higher maternal mortality ratio than to the Country for the measuring the maternal health. Though, the progress made has been uneven and inequitable, and many women still lack access to maternal and reproductive health care. In India, as in many other settings, social structures prevent women from having access to maternal and reproductive health care. Adolescent and illiterate mothers and those living in hard to reach areas still have much greater chance of dying in childbirth. In rural and remote areas of the country the status of adolescent girls are especially vulnerable as teenage marriage and pregnancies are very high. This article disseminating the complications during pregnancy and its socio-demographic factor as a risk through the adequate statistical test results. The studied population are vulnerable and the district (Dindori) is defined most backward and still ranked in India where the study was done. Conducted study in 2009-10 among the concern tribe reported about $72 \%$ Baiga women had taken at least one ANC checkups having low level of knowledge of such services. ${ }^{8}$ As well as the traditional cultural norms are an emerging factor for newborn morbidities among Baiga. ${ }^{20}$ 
Hence, the present article aims to examine the level of prevalence of multiple complications and the measure the independent effect of socio-demographic factors on reported particular complications of pregnancy among currently married women. About The Tribe: This Baiga tribe is one of most ancient \& vulnerable aboriginal tribe of Madhya Pradesh. They are socially and economically backward, illiterate segment of population. The habitat area is known as Baigackak of district Dindori spread in three Blocks. They are living in dense forest, hilly area and tattooing is an integral part of their fashion/lifestyle of women. They are isolated from the main stream of the country, their economy depend on agriculture, forest product and labor work.

\section{Materials and Methods}

The study was carried out among Baiga tribe in Dindori District of Madhya Pradesh in 2013-2016. A cross sectional survey was carried out in 24 selected villages. The data were collected by trained investigators through structured questionnaire with maintaining utmost privacy as per the convenience of the respondents after taking their written consent. Information on maternal and child care was collected from ever married women aged 15-49 years who had a live birth in the last three years. A pre-structured and pre tested interview questionnaire envisaged by trained investigators. Each respondent gave informed written consent after explaining the content, purpose and procedure of the study. In the case of illiterate gave consent in the form of thumbing. The total populations 2548 of 556 households were surveyed in 24 villages. A total of 584 ever married women identified for interview on the issues. Out of them 367 women who have eligible for antenatal care of them $82.3 \%$ women had taken ANC checkups. For the estimation of their pregnancy related complications were gathered through conducted individual interview method. The inclusion criteria were used: ever married women age between 15 to 49 years, who have expose to maternity preceding last three years, available at the time of survey, and willing to give written consent. Information on ANC coverage, place of delivery, etc was collected from women who had a live birth. Along with the obstetric complications which refer to the disruptions and disorders of pregnancy, delivery and early neonatal period was also collected for morbidity profile. For pregnancy related complications investigator were ask to respondent that when you were pregnant did you experience any of the problems/complication. The mother were asked whether at any time during the pregnancy had any experience of pregnancy related complications. The data were analyze with SPSS software version 20.0. A p-value of $<0.05$ was considered as statistical significant for the valuable outcomes.

\section{Results}

\section{Respondents characteristics}

The distribution of women by their age, child birth orders, age at marriage and educational status given in figure-1. About $80 \%$ women were found in 20-29 years of age,
$15.5 \%$ in below 20 years as younger and $4.6 \%$ women were having 30 and above years. A significant proportion of women were seen with 2 to 4 child. It was also found a significant proportion of women were married before the legal age at marriage 19 years of age. The educational status of women were found very poor as about $74 \%$ having illiterate, $17 \%$ women educated up to middle school and $9.5 \%$ women up to primary school.

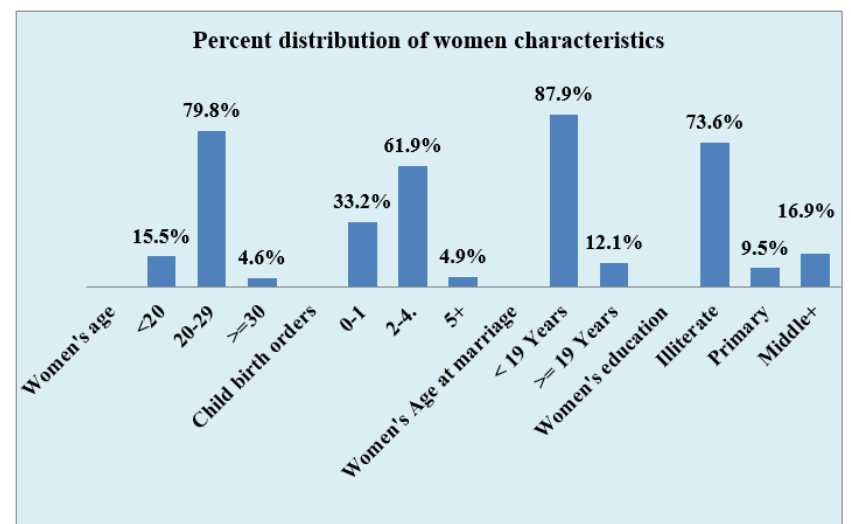

Fig. 1: Percent distribution of respondents (women) according to their background as socio-demographic characteristics of Baiga population in Dindori district of $\mathrm{M}$. $\mathrm{P}$

\section{Prevalence of multiple complications during pregnancy}

The multiple complications during pregnancy were observed on the basis of conducted interview method with the women during the survey. The information regarding various complications during pregnancy like difficulty with daylight vision night blindness, blurred vision, convulsion not from fever, swelling of the leg, body and face, excessive fatigue, anemia and any vaginal bleeding were collected in the outline of multiple response. All responses were held in reserve confidential and anonymous. Out of 367 eligible women who experienced maternity during preceding the last three years during the survey period. Around 131 (35.7\%) women were reported their experiences of complications which faced during the pregnancy. The prevalence of multiple complications are revealed as Night blindness (28.6\%), Blurred vision (10.9\%), Convulsion (21.3\%), Swelling of the legs, body \& face (26.7\%), Excessive fatigue (4.6\%), Anemia (35.7\%) and Vaginal bleeding (4.9\%) presented in Fig. 2. 




Fig. 2: Percent distribution of multiple complications during pregnancy among vulnerable Baiga women in Dindori district of Madhya Pradesh

3. Relationship between pregnancy related complications/morbidities with their socio-demographic characteristics (Resulted by-Logistic Regression Analysis)

Women in rural tribal areas, each and every one women who have reported particular of pregnancy related complications were considered as dependent (predictor) variables for the analysis to estimate the level of risk. This predictor variables was dichotomized as the presence or absence of complications as reported by individuals women at the time of interviewing. In this concern, literature implies that the occurrence of complications could probably be influence by socio-economic factors (independent variables) as education, income, etc as well as by demographic factors such as age, age at marriage, etc and other reasons. Therefore, we have option to determine the which factors responsible for the arising morbidities in vulnerable population. Thus, for taking these issues into the account, the considered the variables as follows; women's age, previous birth order, age at marriage and women's education as covariate variables $\&$ experiences of pregnancy related complications as dependent variables. For the risk estimation and interpretation, Logistic Regression analysis was done to measure the independent effect of sociodemographic variables on reported particular problems of pregnancy in clubbing both the group (intervention \& control) population to find out the overall risk in studied segment. It's also done separately in intervention and control group population for comparing the problems. The logistic regression models were run for the particular seven measures of complications and presented the estimated effects of covariates (socio-demographic variable) on such pregnancy related complications. The coefficients of risk as odds ratios $[\operatorname{Exp}(\mathrm{B})]$ for each covariate are tabulated. The significant was considered with $5 \%, 1 \%$ and $0.1 \%$ levels of probability found less than $(p<0.05), \quad(p<0.01)$ and $(p<0.001)$. The outcome of results discussed in total targeted population in details.

To find out the risk factors associated and responsible for the pregnancy related complications done the Logistic Regression analysis for the results (Table 1). Complications distributed in three age groups, early (less than 20 years), prime (20-29 years) and elderly (30-49 years) age of reproductive span to find out the problems. The results of this analysis revealed that the prime age group (20-29years) of women and elderly aged 30+ years were found significantly associated with complications of night blindness, anemia and blurred vision $(\mathrm{p}<0.05)$ while vaginal bleeding strongly associated $(\mathrm{p}<0.01)$ among elderly women. Pregnancy related complications particularly swelling, excessive fatigue, anemia were found more likely among women who have experiences of high parities (birth order) compared to lower birth order. The women who married before 19 year of age have less likely to occurrences of the problems of night blindness and swelling compared to women who got married after the completion of aged 19 years. Educated women have less likely the chance to exposure the problems except the excessive fatigue which is significantly higher among women who were 5 years schooling. The tribe have malnutrition which may be the cause of complications and low utilization of $\mathrm{MCH}$ services along with low consumption s IFA tablets, etc. Summaries as night blindness, anemia and blurred vision were found significantly among prime and elderly aged women while vaginal bleeding among elderly women only. High birth order, lower age at marriage, illiteracy were found more likely to arise the complications and effect of low education affected significantly for excessive fatigue in target population (including intervention and control areas).

Table 1: Outcomes of estimated risks of pregnancy related complications / morbidities according to their socio-demographic characteristics using Logistic Regression Analysis among the Baiga women in Dindori district of Madhya Pradesh (2013 to 2016).

\begin{tabular}{|l|c|c|c|c|c|c|c|}
\hline \multirow{2}{*}{$\begin{array}{l}\text { Socio-demographic } \\
\text { Variable }\end{array}$} & \multicolumn{6}{|c|}{ Estimated coefficient of the Risk (B) according to socio-demographic variables (Each } \\
& $\begin{array}{c}\text { Night } \\
\text { complication recoded yes=1, no=2) }\end{array}$ & $\begin{array}{c}\text { Blurred } \\
\text { vision }\end{array}$ & Convulsion & Swelling & $\begin{array}{c}\text { Excessive } \\
\text { fatigue }\end{array}$ & Anemia & $\begin{array}{c}\text { Vaginal } \\
\text { bleeding }\end{array}$ \\
\cline { 2 - 8 } & & & & & & & \\
\hline $\begin{array}{l}\text { Women's age } \\
<20(\mathrm{R})\end{array}$ & $4.366^{*}$ & $6.457^{*}$ & 0.984 & 1.222 & 4.886 & $0.126^{*}$ & 6.229 \\
$20-29$ & $3.485^{*}$ & $4.978^{*}$ & 0.900 & 1.079 & 1.463 & $0.189^{*}$ & $4.821^{* *}$ \\
$>=30$ & & & & & & & \\
\hline $\begin{array}{l}\text { Previous birth order } \\
0-1(\mathrm{R})\end{array}$ & 0.512 & 0.000 & 0.516 & 1.438 & 1.367 & 2.371 & 0.532 \\
$2-4$ & & & & & & \\
\hline
\end{tabular}




\begin{tabular}{|l|c|c|c|c|c|c|c|}
\hline 5+ & 0.403 & 0.000 & 0.477 & 1.330 & 1.337 & 1.653 & 1.040 \\
\hline $\begin{array}{l}\text { Women's age at marriage } \\
\text { < 19 Years }\end{array}$ & & & & & & & \\
>=19 Years & 0.507 & 1.106 & 1.623 & 0.887 & 2.540 & 1.245 & 2.338 \\
\hline Women's education & & & & & & & \\
Illiterate (R) & 0.842 & 0.991 & 0.961 & 1.172 & $2.799 * *$ & 1.561 & 2.040 \\
Primary & 0.645 & 0.415 & 0.737 & 0.729 & 0.600 & 1.379 & 0.556 \\
Middle+ & 367 & 367 & 367 & 367 & 367 & 367 & 367 \\
\hline$N$ & 1.272 & 20.208 & 1.725 & 0.646 & 0.947 & 1.116 & 0.655 \\
\hline
\end{tabular}

(R) Reference category

$* p<0.05$, ** $p<0.01$

\section{Discussion}

In all the studied population prevalence of multiple complications as anemia (35.7\%), night blindness $(28.6 \%)$ and swelling $(26.7 \%)$ were found frequently. More than one-fourth of women suffering by these pregnancy related complications. The estimated prevalence of multiple complications such as blurred vision (10.9\%), convulsion (21.3\%) and swelling (26.7\%) were found higher in this studied population as compare to rural area of India ${ }^{19}$ like the blurred vision $7.2 \%$, convulsion $11.3 \%$ and swelling $24.1 \%$. When follow the comparison between intervention and control areas regarding the complications, it was found little lower in intervention area. The socioeconomic cause as a factor prime age (20-29) and elderly age group(30+) were found statistically significant for the behind and higher birth orders, age at marriage less than 19 years and illiteracy were found likely responsible.

In India, substantial amount of pregnant women have been at the risk of serious obstetric complications, most of them had been suffering from multiple complication. ${ }^{13-15}$ This tribe have low awareness and underutilization of $\mathrm{MCH}$ services due to wrong perception in relation to the pregnancy and safe delivery. ${ }^{9}$ The at hand study was intense on disadvantaged tribal group livelihood in very backward compartment. The findings of the study were shown among the tribal women had experienced complications during pregnancy. The socio-demographic factors were found affecting to the reproductive problems. The occurrence of complications may be due to poor socio economic condition, and so on may due to majority of houses Kachcha (made-mud), dependence on livelihood on forest produce and daily wages. On the basis of findings of this study provided convinced significant insights for health policy interventions for preventing these complication. Although pregnancy related illness and complications during pregnancy and delivery are known significant impact on the fetus loss, leading to poor pregnancy outcomes. ${ }^{11-13}$ The World Bank has estimated that about 74 percent of maternal deaths could be averted if all women have access to interventions in terms of complications of pregnancy and childbirth, especially emergency obstetric care ${ }^{21}$. Even as the interventions that could save their lives are extensively known, but peoples are often not available to those most in need. Maternal health care studies are immense important because of complications of pregnancy and childbirth cause had more deaths and disability than any other reproductive health problems such as millions of women in developing countries experience life threatening and other serious health problems related to pregnancy or childbirth. ${ }^{22}$ The study tribe have poor socioeconomic status and underutilization of maternal health care facility the numerous IEC educations may having talented them for increasing awareness to understanding the issues. ${ }^{23-32}$ The health conditions of mothers and outcomes on the whole still births in the country are the key issues. ${ }^{33-34}$ In sight of the findings of the lessons learn a essential obstetric care desired there for the managing of normal and complicated pregnancy, delivery and the postpartum period for healthier outcome as well as reducing the rate of maternal and child mortality in rural area.

\section{Conclusion}

As a result of poor socio-demographic situation and interior inhabitation characteristics, the women have suffering the pregnancy related multiple complications. Observation directs to very few women had able to sought treatment for their problems due to lack of awareness, transportation facility, financial, time to go for hospital, etc. As it is the reporting the complications during the period of pregnancy by vulnerable women is serious issues which desires to acquire concentration for the policy and interventions in terms for creating building awareness among women who live in reproductive span. In addition to essential obstetric care are also required for proper treatment when mother reported complications during pregnancy for to save life and healthier outcomes.

\section{Acknowledgements}

We sincerely thank to division of reproductive health and nutrition, Indian Council of Medical research, Delhi for providing the financial assistance for this study. We also honestly thanks to the Director, National Institute for Research for Tribal Health, Jabalpur for moral support and necessary steps for smooth functioning of project. We are also grateful to the District authorities particularly BMO of concern $\mathrm{PHC} / \mathrm{CHC}$ and health workers for providing support and concentration throughout the field work/data collection/ intervention. We also appreciative to all the respondents for their cooperation and support. We also express our thanks to investigators and project staffs for field work-data collection \&compilation, data entry, data cleaning and analysis. 


\section{Source of funding}

None.

\section{Conflict of interest}

None.

\section{References}

1. S.S. Mumbare, R Rege. Ante natal care services utilization, delivery practices and factors affecting them in tribal area of North Maharashtra. Indian J Community Med, 2011;36(4):28790.

2. Numbers - Healthy Newborn Network: http://www.healthynewbornnetwork.org/numbers/ Accessed on 2 June 2017

3. Bhatia, J.C. and Cleland, J. Levels and causes of maternal mortality in south India. Studies in Family Planning, 1993;24:301-18. http://dx.doi.org/10.2307/2939224

4. Mc. Carthy, J. and Maine D. A framework for analyzing determinants of maternal mortality. Studied in Family Planning, 1992;23:23-33. http://dx.doi.org/10.2307/1966825

5. Stanton C, Lawn JE, Rahman H, Wilczynska-Ketende K, Hill K. Stillbirth rates: delivering estimates in 190 countries. Lancet 2006;367:1487-94.

6. Gabrysch S, Campbell O. Still too far to walk: literature review 7. of the determinants of delivery service use. BMC Pregnancy Childbirth 2009;9:34.

7. Turan JM, Johnson K, Polan ML. Experiences of women 8 . seeking medical care for obstetric fistula in Eritrea: implications for prevention, treatment, and social reintegration. Glob Public Health 2007;2:64-77.

8. D. Kumar and A.K. Goel. Use of antenatal care services and knowledge among Baiga women in Madhya Pradesh. Indian J Sci Res 2016;7(1):197-200.

9. D. Kumar, A.K. Goel, V. Ghanghoria, P. Ghanghoria. A qualitative study on maternal and child health practices among Baiga tribe of Madhya Pradesh in Central India. J Community Health Manag 2016;3(1):23-7.

10. Population Action International (PAI). 9. How access to sexual and reproductive health service is key to the MDGs 2005; Fact Sheet 31 in series. Washington: Population Action International; 1985.

11. Anandalakshmy PN, Talwar PP, Buckshee K, Hingorani V. 19. Demographic, socio-economic and medical factors affecting maternal mortality - An Indian experience. J Fam Welfare 1993;39:1-4.

12. Registrar General, India. 20. Maternal mortality in India: 19972003: trends, causes and risk factors. New Delhi: Registrar General, India; 2006. p. 1-29.

13. Chaurasia AR. Obstetric risk and obstetric care in central 11. India. Soc Change 2006;36:48-66.

14. Singh P, Pandey A, Aggarwal A. House-to-house survey vs. 10. snowball technique for capturing maternal deaths in India: a search for a cost-effective method. Indian J Med Res 2007;125:550-6.

15. Aggarwal A, Pandey A, Bhattacharya BN. Risk factors for 12 . Maternal mortality in Delhi slums: a community-based casecontrol study. Indian J Med Sci 2007;61:517-26.

16. International Institute for Population Sciences (IIPS) and 17. Macro-Internationals. National Family Health Survey (NFHS3); 2005-06. Mumbai, India: Ministry of Health and Family Welfare, Government of India; 2007.

17. Sun YC, Hung YC, Chang Y, Kuo SC. Effects of a prenatal 18. yoga programme on the discomforts of pregnancy and maternal childbirth self-efficacy in Taiwan. Midwifery 2010;26:e31-6.

18. Sexana D, Vangani R, Mavalankar D.V. and Thomsen, S. (2013) Inequity in maternal health care service utilize- tion in
Gujarat: Analysis of district level health survey data, Global Health Action, 2013;6:1-9.

19. National Family Health Survey (NFHS-3), India 2005-2006

20. D. Kumar, A. Vishwakarma A.K. Goel. Tribal Newborn Culture-An observation. Indian J MCH 2015;17(2).

21. Adam Wagstaff and Mariam Claeson. The Millennium Development Goals for Health: Rising to the Challenges (Washington, DC: World Bank, 2004).

22. EC/UNFPA (2000): Making Pregnancy and Childbirth Safer EC/UNFPA Initiative for Reproductive Health in Asia in cooperation with the German Foundation for World Population.

23. Vishwakarma A, A. K Goel, and D Kumar. Indigenous knowledge of post natal care practices: An evidence from primitive Baiga in Madhya Pradesh: SRF , A Q J Multidiscip Res 2016;3(1).

24. Kumar D, A. K Goel. Understanding mothers awareness about maternal health care services among baiga tribe in Madhya Pradesh. Indian J Res 2016.

25. Kumar Dinesh, A. K Goel, Rajasubramaniam Shanmugam. Determinants of utilization of maternal health care services among Baiga Community in Dindori district, Madhya Pradesh, India. Glob J Multidiscip Stud 2016;5(7).

26. Kumar Dinesh, A.K. Goel and T.B Singh: Women attitudes determination among who had not used antenatal care service during pregnancy in Central India: a logistic regression analysis. J Community Health Manag 2016;3(4):178-84.

27. Kumar Dinesh, A.K. Goel and T.B Singh: Estimation of risk factor for conducting delivery at home among Baiga women in Madhya Pradesh: A Multinomial logistic regression analysis. Int J Sci Res 2017;6(2).

28. D. Kumar, A. K. Goel: Obstetric complications during pregnancy \& delivery: Cross-sectional study among Baiga tribe in Madhya Pradesh. Asian J Multidiscip Studies, 2016;4(12):1-6.

29. D. Kumar: Effect of socio-demographic factors on first antenatal checkups in first trimester using analysis of Binary Logistic Regression Model: Bulletin of Mathematics and Statistical Research-A Peer Rev Int Res J 2017;5(2):37-44.

30. D. Kumar, T.B. Singh. Measurements of care components during antenatal care checkups among Baiga's women in Madhya Pradesh, India. J Community Health Manag 2017;4(2):38-40.

31. A.K Goel, D. Kumar. Level of knowledge on maternal health care among Baiga tribe of Madhya Pradesh. Tribal Health Bulletin, Vol.23,no. 2, July 2016;23(44-50.

32. D. Kumar: Effectiveness of IEC-interventions for improving the utilization of maternal and child health care services among vulnerable population in Madhya Pradesh. NIRTH-Update, Vol.2, No.1, May 2017, page2-5.

33. T.B. Singh, D. Kumar. Maternal health status in India. $J$ Community Health Manag 2016;3(2):95-6.

34. D. Kumar, T.B. Singh. Stillbirth issues and challenges in India. J Community Health Manag 2017;4(2):47-9.

How to cite this article: Kumar D, Singh TB, Ghanghoria P, Ghanghoria V. Pregnancy related complications and its association with socio-demographic factors in Central India: A logistic regression hypothesis. J Community Health Manag 2019;6(3):72-6. 